Fixed Point Theory, 23(2022), No. 1, 143-162

DOI: $10.24193 /$ fpt-ro.2022.1.09

http://www.math.ubbcluj.ro/ nodeacj/sfptcj.html

\title{
ON THE FIXED POINT INDEX FOR SUMS OF OPERATORS
}

\author{
SALIM BENSLIMANE*, SMAÏL DJEBALI** AND KARIMA MEBARKI*** \\ *Laboratory of Applied Mathematics, Faculty of Exact Sciences, \\ Bejaia University, 06000 Bejaia, Algeria \\ E-mail: salim.bens1993@gmail.com \\ ** Department of Mathematics, Faculty of Sciences, \\ Imam Mohammad Ibn Saud Islamic University (IMSIU), \\ PB 90950. Riyadh 11623, Saudi Arabia \\ and \\ Laboratoire "Théorie du Point Fixe et Applications" \\ ENS, PB 92 Kouba. Algiers, 16006. Algeria \\ E-mail: djebali@hotmail.com \\ *** Laboratory of Applied Mathematics, Faculty of Exact Sciences, \\ Bejaia University, 06000 Bejaia, Algeria \\ E-mail: mebarqi_karima@hotmail.fr
}

\begin{abstract}
We have obtained some new Krasoneslskii type fixed point theorems for the sum of two operators $T+F$, where $T$ is expansive with constant $h>1$ and $I-F$ is a $k$-set contraction with $k<h$. The existence results are based on a fixed point index for these classes of mappings. Various fixed point theorems are derived in cones and in translates of cones of some Banach spaces. Two examples of application are included to illustrate the theory.
\end{abstract}

Key Words and Phrases: Sum of operators, cone, fixed point index, $k$-set contraction, expansive mapping, Krasnoselskii's Theorem.

2020 Mathematics Subject Classification: 37C25, 47H10, 58J20.

\section{INTRODUCTION}

\section{ACKNOWLEDGMENT.}

The authors are grateful to the Direction Générale de la Recherche Scientique et de Développement Technologique in Algeria for supporting this work.

\section{REFERENCES}

[1] R.P. Agarwal, D. O'Regan, Topological Degree Theory and Applications, Series in Mathematical Analysis and Applications, Vol. 8. Taylor and Francis Group, New York, 2006.

[2] H. Amann, On the number of solutions of nonlinear equations in ordered Banach spaces, J. Functional Analysis, 11(1972), no. 4, 346-384. 
[3] R.I. Avery, D.R. Anderson, R.J. Krueger, An extension of the fixed point theorem of cone expansion and compression of functional type, Comm. Appl. Nonlinear Anal., 13(2006), no. 1, $15-26$.

[4] J. Banas, K. Goebel, Measures of Noncompactness in Banach Spaces, Lecture Notes in Pure and Applied Mathematics, 60 Marcel Dekker, Inc., New York, 1980.

[5] T.A. Burton, A fixed-point theorem of Krasnoselskii, Appl. Math. Lett., 11(1998), no. 1, 85-88.

[6] C. Corduneanu, Integral Equations and Stability of Feedback Systems, Academic Press, New York, 1973.

[7] K. Deimling, Nonlinear Functional Analysis, Springer-Verlag, Berlin, Heidelberg, 1985.

[8] S. Djebali, Fixed point theory for 1-set contractions: a survey, "Applied Mathematics in Tunisia", Proceedings of the International Conference on Advances in Applied Mathematics, Hammamet, Tunisia, December 2013. Series: Springer Proceedings in Mathematics \& Statistics, Springer-Birkhäuser, Vol. 131(2015), 53-100.

[9] S. Djebali, K. Mebarki, Fixed point index on translates of cones and applications, Nonlinear Studies, 21(2014), no. 4, 579-589.

[10] S. Djebali, K. Mebarki, Fixed point index theory for perturbation of expansive mappings by $k$-set contraction, Top. Meth. Nonlinear Anal., 54(2019), no. 2, 613-640.

[11] D. Guo, Y.I. Cho, J. Zhu, Partial Ordering Methods in Nonlinear Problems, Shangdon Science and Technology Publishing Press, Shangdon, 1985.

[12] D. Guo, V. Lakshmikantham, Nonlinear Problems in Abstract Cones, vol. 5, Academic Press, Boston, Mass, USA, 1988.

[13] M.A. Krasnoselskii, Two remarks on the method of successive approximations, Uspekhi Mat. Nauk, 10(1955), 123-127.

[14] M.A. Krasnoselskii, Fixed points of cone-compressing or cone-extending operators, Soviet Math. Dokl., 1(1960), 1285-1288.

[15] M.A. Krasnoselskii, Positive Solutions of Operator Equations, Noordhoff, Groningen, The Netherlands, 1964.

[16] M.K. Kwong, On Krasnoselskii's cone fixed point theorem, Fixed Point Theory Appl. 2008, Art. ID 164537,18 pp.

[17] M.K. Kwong, The topological nature of Krasnoselskii's cone fixed point theorem, Nonlinear Anal., 69(2008), 891-897.

[18] D. O'Regan, Fixed-point theory for the sum of two operators, Appl. Math. Lett., 9(1996), no. $1,1-8$.

[19] D. O'Regan, R. Precup, Compression-expansion fixed point theorem in two norms and applications, J. Math. Anal. Appl., 309(2005), no. 2, 383-391.

[20] W.V. Petryshyn, Remarks on condensing and k-set-contractive mappings, J. Math. Anal. Appl., 39(1972), 717-741.

[21] W.V. Petryshyn, Fixed point theorems for various classes of 1-set-contractive and 1-ballcontractive mappings in Banach spaces, Trans. Amer. Math. Soc., 182(1973), 323-3582.

[22] D.R. Smart, Fixed Point Theorems, Cambridge University Press, Cambridge, 1980.

[23] T. Xiang, S.G. Georgiev, Noncompact-type Krasnoselskii fixed-point theorems and their applications, Math. Methods Appl. Sci., 39(2016), no. 4, 833-863.

[24] T. Xiang, R. Yuan, A class of expansive-type Krasnoselskii fixed point theorems, Nonlinear Anal., 71(2009), no. 7-8, 3229-3239.

Received: March 17, 2020; Accepted: September 12, 2020. 
